\title{
Organisation and outcomes in social enterprising: comparing Europe and the Middle East and North Africa
}

Haya Al-Madadi, Imane El aouissi, Maria Baijou, Mohamed Kamal Zaraba, Oumaima El Azzouzi, Oussama Er-rady, Salma El Haddaji and Yassine Errachid

School of Business,

Al Akhawayn University,

Ifrane, Morocco

Email: h.almadadi@aui.ma

Email: imane.elaouissi@gmail.com

Email: M.baijou@aui.ma

Email: kamal.zaraba0@gmail.com

Email: elazzouzioumaima@yahoo.fr

Email: o.er-rady@aui.ma

Email: s.elhaddaji@aui.ma

Email: errachidyassine@gmail.com

\section{Thomas Schøtt*}

Department of Management,

University of Agder,

Kristiansand, Norway

and

Department of Entrepreneurship and Relationship Management,

University of Southern Denmark,

Kolding, Denmark

Email: tsc@sam.sdu.dk

*Corresponding author

\begin{abstract}
How is social enterprising pursued in Europe and MENA? A representative sample of 92,208 adults in Europe and MENA was surveyed for the Global Entrepreneurship Monitor. Participation in social entrepreneurship is wider in Europe than in MENA. Society and environment are valued in social enterprises more in MENA than in Europe. Informal sources of financing prevail in MENA whereas formal sources dominate in Europe. Market orientation is enhanced when economy of enterprising is valued rather than society and environment. Reinvestment is pursued by women more than by men. Innovation in social enterprises is higher in MENA than in Europe. Expectation for growth is coupled with use of formal and informal sources of financing. Assessment of impact is extensive for female-led enterprises and promoted by market orientation. The study contributes to knowledge about social entrepreneurship as organised and pursued as a social institution in society, but differently in Europe and MENA.
\end{abstract}


Keywords: social enterprises; social value; environmental value; economic value; Global Entrepreneurship Monitor; GEM.

Reference to this paper should be made as follows: Al-Madadi, H., El aouissi, I., Baijou, M., Zaraba, M.K., El Azzouzi, O., Er-rady, O., El Haddaji, S., Errachid, Y. and Schøtt, T. (2020) 'Organisation and outcomes in social enterprising: comparing Europe and the Middle East and North Africa', MENA J. Cross-Cultural Management, Vol. 1, No. 1, pp. $20-41$.

Biographical notes: Haya Al-Madadi completed her Bachelor's in Business Administration at the $\mathrm{Al}$ Akhawayn University in Ifrane, Morocco, and is now doing her MBA at the same university. She worked on this paper in her research methodology seminar.

Imane El aouissi is a graduate student in Al Akhawayn University in Ifrane, Morocco, who specialises in Finance. She received her Bachelor's in Business Administration from the American University of Leadership, Morocco. She is currently working on her MBA thesis which is about the impact of liquidity on profitability of banks listed in Casablanca Stock Exchange.

Maria Baijou obtained her Bachelor's degreein Economics at the University Mohamed V in Rabat, Morocco, and had been working with Moussdak Bouchta company. She is now a Master's student in School of Business Administration, majoring in Finance at the Al Akhawayn University.

Mohamed Kamal Zaraba is a Master's of Business Administration student at the Al Akhawayn University in Ifrane, Morocco. He worked on this research paper while taking a course with Dr. Thomas Schøtt on research methodology.

Oumaima El Azzouzi obtained her Bachelor's in General Management at the private university of Marrakech, Morocco. She is currently a Master's student in the School of Business Administration, majoring in Finance, at Al Akhawayn University.

Oussama Er-rady obtained his Bachelor's at the Al Akhawayn University and is now at his last semester of MBA. He worked as a part-timer in many departments within the university. He is currently the administrator of the Center for Learning Excellence within Al Akhawayn University. He worked on this paper while taking the research and methodology course.

Salma El Haddaji is currently pursuing her MBA at Al Akhawayn University in Ifrane. She received her Bachelor's degree in Business Management and Marketing from 'Ecole Supérieure des Métiers de Commerce, de Gestion et d'Informatique' (EMCGI) in Tangier, Morocco. She has been a part time assistant to professors for two semesters. She is interested in entrepreneurship and is a delegate at United Nation Youth Agenda 2030.

Yassine Errachid is an MBA student at the Al Akhawayn University in Ifrane. He received his Bachelor's in Supply Chain Management from the ESITH. $\mathrm{He}$ is interested in the impact of education on social enterprising in the MENA region.

Thomas Schøtt obtained his $\mathrm{PhD}$ at the Columbia University and Postdoc at the Yale University. He has been an Assistant and Associate Professor at the University of Pittsburgh, and Professor at the University of Southern Denmark, and is now Professor at University of Agder, Norway. He worked on this paper 
while he was a Visiting Professor at the Al Akhawayn University and Distinguished Visiting Professor at the American University in Cairo. His publications have appeared in numerous books and journals, including Research Policy, Small Business Economics, and Entrepreneurship and Regional Development.

\section{Introduction}

One morning, Rani Dajani, mother of four brought some of their children's books to a public space in her neighbourhood, a place in a mosque in Jordan, which the imam had lent to her. She began reading stories for the kids in the neighbourhood. Her purpose was to engage them passionately in reading stories. She had perceived a demand among kids for engaging stories, which was not met by the more serious educational and religious texts, and she realised the opportunity to meet their need by reading stories to them. Her endeavour began informally and was non-economic in that it relied on donated books, borrowed space, and volunteers whom she trained in reading stories. The endeavour grew, became formal by registering as a non-profit organisation, and employed a staff. The enterprise adopted a market orientation by producing innovative materials, notably children's books and programs for training readers, for sale to institutions wanting to pursue story telling through reading to children. The profits are reinvested in the enterprise. The impact on children is assessed, partly to enhance legitimacy among foundations and agencies funding the enterprise. This organisation We Love Reading exemplifies social enterprises analysed in this study (http://www.welovereading.org/).

Social entrepreneurship here denotes activities, initiatives and organisations that have specific social, environmental and community objectives. This is a broad definition, in that this social enterprising comprises both formal and informal endeavours, includes both endeavours run as businesses and endeavour that are not run as businesses, and also encompasses both privately owned enterprises and endeavours that are not owned privately (Peredo and McLean, 2006). Accordingly, social entrepreneur denotes the role that consists in starting or leading activities, initiatives and organisations with such a specific objective (Bornstein, 2004).

People's enterprising is embedded in their society, which channels, empowers and constrains enterprising (Stephan et al., 2014). Societies differ in their social entrepreneurship. Societies differ in their culture, religion, economy and social institutions, and their diverse institutions create differences in their social entrepreneurship (Monge, 2018).

We here focus on two societies, Europe and the Middle East and North Africa (MENA). Economically, they differ in that Europe is wealthier. Culturally, they differ, traditional culture prevails in MENA whereas secular-rational culture prevails in Europe. Such economic and cultural differences expectedly influence social enterprising (Defourny and Nyssens, 2010; Kabbaj et al., 2016).

Our research question is, how is social entrepreneurship pursued in Europe and in the MENA?

Our approach adopts a multistage perspective in that we consider the process from early phase when people become social entrepreneurs, through the starting phase with 
up-start funding from a variety of sources, and through the organisation of the enterprise, to outcomes such as innovation and expectations for growth. Our approach also adopts a multilevel perspective in that we examine behaviour of social entrepreneurs in the context of their social enterprises, and wider, in the context of society - Europe and MENA with their different institutions and cultures (Saebi et al., 2019).

The following sections first reviews the most relevant theoretical perspective and literature, then describes our research design, addresses the research question, and concludes with a discussion of social enterprising in Europe and MENA.

\section{Theoretical background}

Social enterprising is viewed as a set of outcomes shaped by the background of personal and organisational characteristics which is influenced by the context, society in Europe and MENA. This scheme is illustrated in Figure 1.

Figure 1 Conceptual scheme of social enterprising

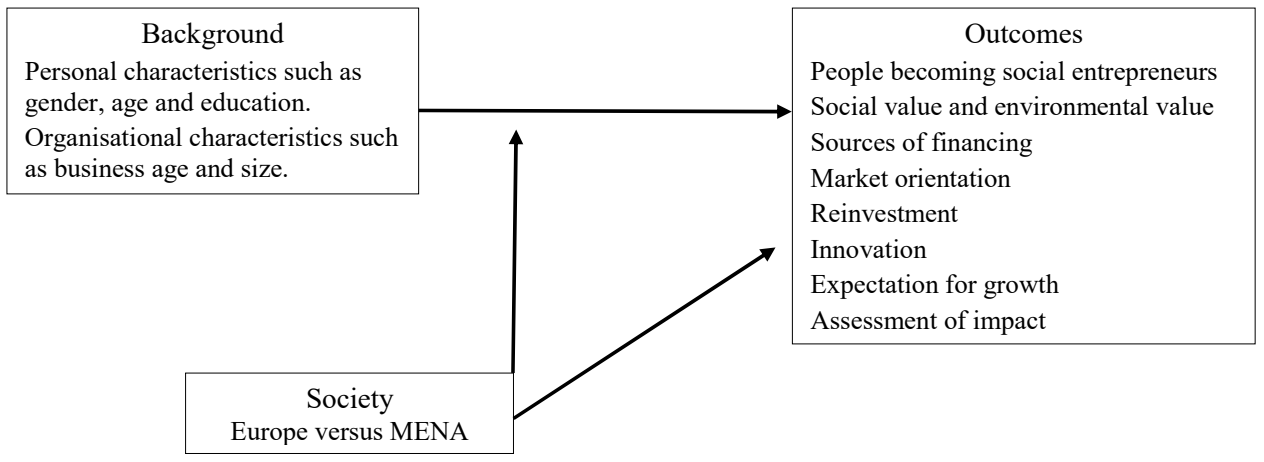

A growing body of literature offers theory and evidence about social entrepreneurship (Hoogendoorn et al., 2010), also about various outcomes that we examine:

- $\quad$ people becoming social entrepreneurs

- $\quad$ social and environmental value versus economic value of social enterprises

- use of formal and informal sources of financing

- market orientation

- reinvestment

- innovation in social enterprises

- $\quad$ expectation for growth of social enterprises

- conduct of assessments of impact on society and environment.

Some people participate in social entrepreneurship, but most do not (Bosma et al., 2016). Globally, in the world as a whole, around $10 \%$ of the adults are social entrepreneurs (Bosma et al., 2016). But participation differs among societies, it is especially high in Australia and the USA, and especially low in South-East Asia (Bosma et al., 2016). 
The social entrepreneurs are men more often than women, but the gender gap in social entrepreneurship is narrower than the gender gap in commercial entrepreneurship (Bosma et al., 2016). Social entrepreneurs tend to have more education than commercial entrepreneurs, and also more than the adult population (Bosma et al., 2016). In our analysis, below, we examine how the probability of being a social entrepreneur is affected by gender, age, education and region, Europe versus MENA.

In some social enterprises, the economy is highly valued, while other place higher value on the social and on the environmental outcomes of the enterprise. The mix of values may reflect concerns of managers, as found in a study in Slovenia, where managers' personal concern for the environment reduces their focus on economic results of the enterprise and enhances the environmental responsiveness of the enterprise (Potocan et al., 2019).

A variety of sources of financing of social enterprises are utilised for starting social enterprises. Social entrepreneurs provide much own financing, but much also comes from family, friends, grants awarded by private foundations and public agencies and use of sources differ among societies (Jamali et al., 2016). In MENA and Europe, social enterprises focus on social benefits; whereas, in the USA, social enterprises focus on achieving sustainable revenue generation and self-sufficiency. This means that European and Arab social enterprises need to look for alternative sources of funding to keep their social mission alive (ibid.)

Access to financing is especially critical and difficult for young potential entrepreneurs, who often come from unemployment. This is well known and considered problematic. Most recently, in October 2019, the King of Morocco focused on the negative image of banks in his opening speech to the Moroccan Parliament, "this image is justified by facts, such as the difficult access of young entrepreneurs to credit, the poor support of graduates and small and medium-sized enterprises during their creation." The king also urged the banks to "promote access to bank loans for the largest number of qualified young people with projects and from different social categories to enable them to engage in entrepreneurship and to have the best chances of success." Finally, during the opening of the parliament, the king wished to recall "the social responsibility that falls on financial firms, as well as its necessary participation in constructive initiatives that promote sustainable development, whether it is social, humanitarian, or environmental" (Moroccan Press Agency and HuffPost Morocco, 2019). In our analysis, below, we examine how sources of funding are affected by gender, age, education and region, Europe versus MENA.

Social enterprises may produce goods and services sold in a market (Austin et al., 2006). Market orientation of social enterprises is found to be related to risk-taking and progressiveness, but seemingly unrelated to innovation in the enterprises (Ma et al., 2012). Market orientation enhances social performance in terms of job creation (ibid.). Market orientation may be pursued with a variety of commercial practices having different impacts. Market disruptiveness capability has been found to enhance economic performance but not social impact (Bhattarai et al., 2019).

Profits resulting from a market orientation of a social enterprise may be reinvested, and the reinvestment may thus promote its pursuit of social purpose. The decision to reinvest depends on the background of the social entrepreneur, e.g., female social entrepreneurs reinvest less than male social entrepreneurs (Wellalage and Reddy, 2017). Reinvestment differs among societies depending on the laws and rules of management (Demirbag et al., 2015). 
Innovation may be pursued in social enterprises. Perrini and Vurro (2006) claimed that innovation can be used in social entrepreneurship, by correlating the enterprises' mission statements and social opportunities so as to create a social change or transformation. However, a successful social innovation fundamentally requires a business model that would fit the unsatisfied need or demand. In this business model, social innovation can be seen either through the products or services to be offered, network relations, factors, or methods or processes. Another investigation by Phillips et al. (2014) addressed the question closely. The researchers defined social innovation as the set of activities and services provided, in an innovative way, pursuing a specific goal that should serve a social need. Using a systematic review, the research displayed that social innovation and social entrepreneurship converge into common overlaps, notably in the process of finding opportunities for meeting unsatisfied social needs.

An expectation for growth of a social enterprise may prevail. A study (Santos et al., 2015) discusses four potential types of hybrid organisations that should be managed effectively to reach higher growth expectations. The main question discussed by the authors is how the successful alignment of business models with organisational designs can lead social enterprises to attain higher financial stability and growth. Their typology offers a sustainable value creation leading to strong sets of growth. Another study (Sud et al., 2008) suggests that the key for social enterprises to achieve a long-term growth is achieving a competitive advantage. The achievement of competitive advantage lies behind the extent to which social entrepreneurs can detect new solutions that might be seen as 'the' solutions to some existing problems. The ways by which social enterprises can assess these new solutions effectively is a competitive advantage that provides a focus on the growth expectations.

The social and environmental impact of social enterprises may be assessed. Impact assessment is crucial to their legitimacy and many supporters demand assessment, especially when performance is not assessed in form of profits and survival in a market. A study in MENA indicates that people believe that social enterprises create jobs, but many people also believe that social entrepreneurs actually only focus on personal profit (Abdou et al., 2010). Impact assessment appears more prevalent and more positive in Europe (Schneider et al., 2015).

\section{Research design}

The issues of people's pursuits of social entrepreneurship concern the populations of adults in Europe and MENA. The adults have been surveyed in 2015 by the Global Entrepreneurship Monitor (GEM) (Global Entrepreneurship Research Association, 2020; Bosma et al., 2016). The data are readily available in the public domain at http://www.gemconsortium.org. The data have been used in a few scholarly publications (Bosma et al., 2016; Monge, 2018).

\subsection{Sampling}

GEM sampled in the populations of adults in Europe and MENA in two stages. In the first stage, countries were selected. In 2015 the survey covered 24 countries in Europe, namely Belgium, Bulgaria, Croatia, Estonia, Finland, Germany, Greece, Hungary, 
Ireland, Italy, Latvia, Luxemburg, Macedonia, Netherlands, Norway, Poland, Portugal, Romania, Slovakia, Slovenia, Spain, Sweden, Switzerland, and the UK. These countries seem rather representative of the societies in Europe. The survey covered six countries in MENA, Egypt, Iran, Lebanon, Morocco, Tunisia and Turkey. These countries seem fairly representative of the societies in MENA.

In the second stage, adults age 18 to 64 years old are sampled randomly within each selected country, and thereby sampled representatively. As this process is representative in both stages, the resulting sample of adults is representative. The representativeness implies that our findings can be generalised to the populations of adults in Europe and MENA. The sample comprises 92,208 adults. This is used for analysing adults' participation in social entrepreneurship. For analysing the social enterprises, we use the subsample of those leading social enterprises, a sample of 3,666 social entrepreneurs.

\title{
3.2 Measurements
}

\subsubsection{People becoming social entrepreneur}

The survey identified a social entrepreneur by asking every adult:

\begin{abstract}
"Are you, alone or with others, currently trying to start or currently leading any kind of activity, organization or initiative that has a particularly social, environmental or community objective? This might include providing services or training to socially deprived or disabled persons, activities aimed at reducing pollution or food-waste, organizing self-help groups for community action, etc."
\end{abstract}

The variable is coded 1 if the adult is a social entrepreneur, and 0 if not.

\subsubsection{Social and environmental value of a social enterprise contrasted economic value}

The kinds of values pursued in a social enterprise were measured by first contrasting the social and environmental value with the economic value, by asking the social entrepreneur for their dis/agreement with the statement:

"For my organization, generating value to society and the environment is more important than generating financial value for the company."

The social entrepreneur rated extent of dis/agreement on a Likert scale, ranging from 1 for emphasis on economic value up to 5 for value to society and the environment.

\subsubsection{Social value versus environmental value of a social enterprise}

The kinds of values emphasised in the social enterprise were probed further by contrasting the social value to the environmental value, by also asking the social entrepreneur for their dis/agreement with a follow-up statement:

"My organization puts more emphasis on social value than on environmental value."

The social entrepreneur again rated dis/agreement on the Likert scale, going from 1 for emphasis on environmental value up to 5 for emphasis on social value. 


\subsubsection{Sources of financing for social enterprises}

Sources of funding were measured by asking the social entrepreneur who received external financing:

"Have you received or do you expect to receive money - loans or ownership investments - from any of the following to start this activity, organization or initiative?

- $\quad$ Family members?

- Friends or neighbors

- Employer or work colleagues?

- Banks or other financial institutions?

- Private investors or venture capital?

- Government programs, donations or grants?

- Online crowdfunding?"

For each of the seven questions, the response was coded 0 for no, and 1 for yes. We factor analysed the seven variables. The exploration revealed two factors, a factor of informal sources manifest in family, friends and employer, and a factor of formal sources expressed in financial institutions, private capital, government, and crowdfunding. The mean of the first three measurements is an index of informal sources, and the mean of the last four measurements is an index of formal sources.

\subsubsection{Market orientation of a social enterprise}

Market orientation of an enterprise is measured by posing the following statement to the social entrepreneur:

"My organization operates in the market by producing goods and services."

The entrepreneur rated truthfulness on the Likert scale going from 1 for no market orientation up to 5 for strong market orientation.

\subsubsection{Reinvestment in a social enterprise}

Reinvestment is measured by asking the social entrepreneur:

"Profits will be reinvested to serve the social or environmental purpose of my organization?"

The entrepreneur rated reinvestment on a Likert scale, going from 1 for no reinvestment up to 5 for high reinvestment.

\subsubsection{Innovation in a social enterprise}

Innovation is indicated by posing two statements to the social entrepreneur:

"My organization offers products or services that are new to the market."

"My organization offers a new way of producing a product or service." 
The entrepreneur rated truthfulness of each statement on the Likert scale going from 1 up to 5 for increasing innovativeness. The mean is then an index of innovation.

\subsubsection{Growth-expectation in a social enterprise}

Expectation for growth is measured by asking the social entrepreneur about current and future size:

"How many people are currently working for this activity, organization or initiative?"

"How many people, including both present and future employees, will be working for this activity, organization or initiative five years from now?"

Expectation for growth is then measured by the difference, $\log (1+$ expected size $)$ $-\log (1+$ current size $)$.

\subsubsection{Impact assessment in a social enterprise}

Conduct of assessment of impact is measured by asking the social entrepreneur:

"My organization puts substantial effort in measuring its social or environmental impact?"

The entrepreneur rated truthfulness of each statement on the Likert scale going from 1 up to 5 for increasing conduct of impact assessment.

\subsubsection{Other variables}

We analyse effects of gender, age, education, and region, coded as follows:

- $\quad$ gender is coded 0 for men and 1 for women

- $\quad$ age is measured in years

- $\quad$ education, queried as highest degree completed, is here coded in years

- $\quad$ region is coded 0 for Europe and 1 for MENA.

\section{Results}

The following analyses each of the outcomes, namely participation, social and environmental value versus economic value, social value versus environmental value, sources of financing, market orientation, reinvestment, innovation, growth-expectation, and conducting assessment of impact.

\subsection{Peoples' participation in social entrepreneurship in Europe and MENA}

Our first question is, whether participation in social entrepreneurship differs between Europe and MENA. In Europe $4.1 \%$ of adults are social entrepreneurs, and in MENA $3.4 \%$ of adults are social entrepreneurs. The difference is substantial (and statistically significant with $\mathrm{p}<0.001)$. 
The further question is, how are people's participation in social entrepreneurship affected by their background and region? The effects of gender, age, education, and also region upon the probability of being a social entrepreneur or not, are ascertained by a logistic regression (Table 1, first model), in which a statistically significant effect is listed with an asterix, or several when the doubt is especially small, a positive effect is indicated by a positive coefficient, and a negative effect is indicated by a negative coefficient.

The effect of gender is significant and negative, i.e., being woman reduces the probability of being a social entrepreneur. The effect of age is not significant, i.e., being young or old seems not to matter for becoming a social entrepreneur. The effect of education is significant and positive, i.e., higher education increases the probability of being a social entrepreneur. The effect of region is significant and negative, i.e., being in MENA rather than in Europe reduces the probability of being a social entrepreneur.

Table 1 Adults' participation as social entrepreneurs, affected by region, gender, age, and education

\begin{tabular}{lcc}
\hline Region (Europe 0, MENA 1) & $-0.19^{* * *}$ & $1.24^{* * *}$ \\
Gender (male 0, female 1) & $-0.19^{* * *}$ & $-0.18^{* * *}$ \\
Age & 0.00 & 0.00 \\
Education & $0.16^{* * *}$ & $0.18^{* * *}$ \\
Region * gender & & -0.08 \\
Region * age & & -0.01 \\
Region * education & & $-0.09 * * *$ \\
Intercept & $-5.16^{* * *}$ & $-5.40^{* * *}$ \\
$\mathrm{~N}$ adults & 91,042 & 91,042 \\
\hline
\end{tabular}

Notes: Logistic regression. ${ }^{*} \mathrm{p}<0.05,{ }^{* *} \mathrm{p}<0.01$ and $* * * \mathrm{p}<0.001$.

A further question is whether personal background matters differently in the two regions. This question is addressed by including interactions (the product of region and each characteristic) in the logistic regression (the second model in Table 1).

Whether gender has a different effect in the two regions is tested by the coefficient -0.08 in Table 1 . The coefficient is not significant, i.e., the gender effect is similar in the two regions. Whether age has a different effect in the two regions is tested by the coefficient -0.01 . The coefficient is not significant, so the age effect is similar in the two regions, hence there seems to be no age effect in either region. Whether education has a different effect in the two regions is tested by the coefficient -0.09 . This coefficient is significant and is negative, i.e., education has a lower effect in MENA than in Europe. The education effect in Europe is 0.18 and in MENA the education effect is 0.09 (namely 0.18-0.09).

The analysis reported in Table 1 shows that people's participation in social entrepreneurship differs between the two regions. Being a social entrepreneur is affected by personal background, in that being woman rather than man, reduces the probability, age has no significant effect, and education has a positive effect on the probability of being a social entrepreneur. Being a social entrepreneur is also affected by context in that being in MENA reduces the probability of being a social entrepreneur. The effect of personal background, moreover, differs between the regions. The gender effect does not 
differ significantly between the regions. Age has no significant effect in either region. The education has a different effect in the two regions. Education has a positive effect on the probability of being a social entrepreneur in both regions, but the effect is higher in Europe than in MENA.

\subsection{Social and environmental value contrasted economic value}

The first question here is, how are the social enterprises valuing society and the environment in comparison to valuing the economy of the business? In Europe, the mean of the social and environment value is 3.87 and in MENA the mean of the social and environment is 4.03 . The difference is significant $(p<0.05)$. So our first conclusion here is that the social entrepreneurs in MENA attach greater value to the social and environmental than their peers in Europe, whereas the social entrepreneurs in Europe value the economic more than their peers in MENA.

The further question is, how is the value attached to society and environment, in contrast to the value attached to the economy of the social enterprise, influenced by characteristics of the entrepreneur and the enterprise? We ascertain the influence of gender, age and education in a linear regression, Table 2.

The effect of gender is significant and positive, i.e., the value attached to society and the environment is higher in social enterprises led by women than in enterprises led by a man.

The effect of age is significant and positive, i.e., the value attached to society and the environment is higher among older than among younger social entrepreneurs.

The effect of education is significant and positive, i.e., higher education of the social entrepreneur increases the value granted society and environment in the social enterprise.

The effect of region is significant and positive, social enterprises in MENA, contrasted those in Europe, attach greater value to society and environment.

Table 2 Value to society and environment, rather than to the economy of social enterprises, affected by region, gender, age, and education

\begin{tabular}{lcc}
\hline Region (Europe 0, MENA 1) & $0.215^{* * *}$ & 0.160 \\
Gender (male 0, female 1) & $0.122^{* *}$ & $0.105^{*}$ \\
Age & $0.004^{*}$ & $0.004^{*}$ \\
Education & $0.039^{* * *}$ & $0.042^{* * *}$ \\
Region * gender & & 0.144 \\
Region * age & & 0.005 \\
Region * education & & -0.015 \\
Intercept & $3.092^{* * *}$ & $3.083^{* * *}$ \\
N social entrepreneurs & 3,290 & 3,290 \\
\hline
\end{tabular}

Notes: Linear regression with metric coefficients. ${ }^{*} \mathrm{p}<0.05,{ }^{* *} \mathrm{p}<0.01$ and $* * * \mathrm{p}<0.001$.

Our further question here is whether the social entrepreneurs' background affect the value differently in Europe and MENA. This question is addressed by including interactions (the product of region and each characteristic) in the linear regression (the second model in Table 2). 
Whether gender has a different effect in the two regions is tested by the coefficient 0.144. The coefficient is not significant, i.e., the gender effect is similar in the two regions.

Whether age has a different effect in the two regions is tested by the coefficient 0.005. The coefficient is not significant, so the age effect is similar in the two regions.

Whether education has a different effect in the two regions is tested by the coefficient 0.015 . The coefficient is not significant, so education effect is similar in the two regions.

\subsection{Social value contrasted environmental value of social enterprises}

The kinds of values pursued in social enterprises is here probed further in terms of social value contrasted environmental value.

Our first question here is whether Europe and MENA differ in social value contrasted environmental value of enterprises. In Europe, the mean of the social value is 3.55 and in MENA the mean of the social value is 3.77. This difference is significant $(p<0.001)$. Our first conclusion thus is that value is attached to the social, rather than the environmental, more in enterprises in MENA than in enterprises in Europe.

A further question is, how is the value attached to the social, rather than to the environmental, affected by gender, age, education, and region simultaneously? These effects are ascertained in a linear regression (Table 3 ).

Gender affects value attached to the social rather than the environment, in that female social entrepreneurs value the social more than male social entrepreneurs do.

Age does not affect the value, so young and old are similar in the value they attach to the social versus the environment.

Education affect the value significantly and positively, i.e., higher education entails higher value attached to the social compared to the environmental.

Table 3 Value attached to social, rather than environment, affected by gender, age, education and region

\begin{tabular}{lcc}
\hline Region (Europe 0, MENA 1) & $0.242^{* * *}$ & 0.241 \\
Gender (male 0, female 1) & $0.157^{* * *}$ & $0.156^{* * *}$ \\
Age & 0.002 & 0.001 \\
Education & $0.019^{* *}$ & $0.022^{* *}$ \\
Region * gender & & 0.030 \\
Region * age & & 0.005 \\
Region * education & & -0.013 \\
Intercept & $3.157^{* * *}$ & $3.140^{* * *}$ \\
N social entrepreneurs & 3,260 & 3,260 \\
\hline
\end{tabular}

Notes: Linear regression with metric coefficients. ${ }^{*} \mathrm{p}<0.05,{ }^{*} \mathrm{p}<0.01$ and $* * * \mathrm{p}<0.001$.

Our further question here is whether the social entrepreneurs' background affect the value differently in Europe and MENA. This question is addressed by including interactions (the product of region and each characteristic) in the linear regression (the second model in Table 3). 
Whether gender has a different effect in the two regions is tested by the coefficient 0.030 in Table 3 . The coefficient is not significant, i.e., the gender effect is similar in the two regions.

Whether age has a different effect in the two regions is tested by the coefficient 0.005 in Table 3. The coefficient is not significant, so the age effect is similar in the two regions.

Whether education has a different effect in the two regions is tested by the coefficient -0.013 in Table 3 . The coefficient is not significant, so education has a similar effect in the two regions.

\subsection{Sources of financing for social enterprises}

For financing their social enterprises, entrepreneurs use formal and informal sources, both measured numerically on a scale from 0 to 1 . Their use of formal sources is 0.26 on average among the entrepreneurs, and their use of informal source is 0.19 on average. Thus social entrepreneurs are using formal sources more than informal sources.

Differences between the regions is also ascertained by averages. The use of formal sources averages 0.19 in MENA and 0.27 in Europe. This difference is significant $(p<0.001)$. So formal sources are used more in Europe than in MENA. The use of informal sources averages 0.27 in MENA and 0.18 in Europe, a significant difference $(\mathrm{p}<0.001)$. So informal sources are used more in MENA than in Europe. These differences are to be expected, because formal institutions tend to be weaker in developing societies, e.g., MENA, as compared to more developed societies, e.g., Europe.

A further question is, how are formal and informal sources of financing affected by gender, education, age, region, and market orientation? Such effects are ascertained by a linear regression (Table 4).

Formal sources are used less in MENA than in Europe.

The use of formal sources does not differ significantly between female and male social entrepreneurs.

The use of formal sources does not depend discernably on education.

The use of formal sources does not depend on market orientation.

But the use of formal sources depends on age, in that formal source are used less by elderly than by younger social entrepreneurs.

Whether such effects on formal sources differ between Europe and MENA is ascertained by including interactions (Table 4, second model). Gender has no significantly different effect in Europe and MENA.

Education, likewise, has no different effect in the two regions.

Also, market orientation has no discernibly different effect in the regions.

But the age effect differs between regions, it is more positive in MENA than in Europe. The use of formal sources increases with age more in MENA than in Europe. In other words, using formal sources of financing is especially rare for young social entrepreneurs in MENA. This finding is consistent with the call of the King of Morocco on banks to increase funding on young entrepreneurs, as mentioned earlier. 
Table 4 Formal and informal sources of financing, affected by region, gender, age, education and market orientation

\begin{tabular}{lcccc}
\hline & \multicolumn{2}{c}{ Use of formal sources } & \multicolumn{2}{c}{ Use of informal sources } \\
\hline Region (Europe 0, MENA 1) & $-0.124^{* * *}$ & -0.385 & $0.123^{* * *}$ & -0.085 \\
Gender (male 0, female 1) & -0.029 & -0.033 & -0.012 & -0.013 \\
Age & $-0.002^{*}$ & $-0.002^{* *}$ & $-0.002^{*}$ & $-0.002^{*}$ \\
Education & 0.004 & 0.004 & $-0.007^{*}$ & $-0.008^{*}$ \\
Market orientation & 0.004 & 0.003 & 0.003 & 0.004 \\
Region * gender & & 0.058 & & -0.014 \\
Region * age & & $0.006^{*}$ & & 0.005 \\
Region * education & & -0.005 & & 0.005 \\
Region * market orientation & $0.281 * * *$ & 0.019 & & -0.008 \\
Intercept & 696 & $696 * * *$ & $0.345^{* * *}$ & $0.359 * *$ \\
N social entrepreneurs & & 698 & 698 \\
\hline
\end{tabular}

Notes: Linear regression with metric coefficients. ${ }^{*} \mathrm{p}<0.05,{ }^{* *} \mathrm{p}<0.01$ and $* * * \mathrm{p}<0.001$.

Effects upon informal sources are likewise ascertained by linear regression (Table 4, third model).

Region affects informal sources, in that informal financing is more prevalent in MENA than in Europe.

Gender and market orientation do not discernibly affect use of informal financing.

Age affects informal financing negatively, i.e., older social entrepreneurs use informal financing less than younger entrepreneurs do.

Education also reduces the use of informal sources, i.e., educated social entrepreneurs use informal financing to smaller extent than lesser educated entrepreneurs.

The last question concerning financing is whether the effects on informal financing differs between the regions. This question is addressed by including interactions (product of region and each characteristic) (Table 4, last model). None of the interactions are significant, i.e., Europe and MENA are similar in the effects upon informal financing from gender, age, education, and market orientation.

\subsection{Market orientation in social enterprises}

The first question is whether market orientation differs between Europe and MENA. Market orientation averages 3.33 in Europe and averages 3.41 in MENA. The small difference is not significant $(\mathrm{p}=0.41)$.

A further question is, how is market orientation affected by characteristics of the social entrepreneur and the enterprise. These effects are ascertained by a linear regression (Table 5, first model).

Region does not discernibly affect market orientation, also when controlling for characteristics of the entrepreneurs and their enterprises. 
Gender, and also education have no discernible effect on market orientation.

Age affects market orientation, in that elderly have stronger market orientation than younger social entrepreneurs.

Social and environmental value of the enterprise is related negatively to market orientation, i.e., attaching great value to the social and the environment implies less interest in selling goods and services.

Table 5 Market orientation, affected by region, gender, age, education, and social-environmental value

\begin{tabular}{lcc}
\hline Region (Europe 0, MENA 1) & 0.127 & 0.661 \\
Gender (male 0, female 1) & -0.109 & -0.104 \\
Age & $0.007^{*}$ & $0.008^{*}$ \\
Education & 0.003 & 0.015 \\
Social and environmental value rather than economic value & $-0.118^{* * *}$ & $-0.134^{* * *}$ \\
Region * gender & & -0.058 \\
Region * age & & -0.009 \\
Region * education & & -0.056 \\
Region * social and environmental value & & 0.135 \\
Intercept & $3.487^{* * *}$ & $3.341^{* * *}$ \\
N social entrepreneurs & 1,935 & 1,935 \\
\hline
\end{tabular}

Notes: Linear regression with metric coefficients. ${ }^{*} \mathrm{p}<0.05,{ }^{* *} \mathrm{p}<0.01$ and $* * * \mathrm{p}<0.001$.

Whether these effects differ between the two regions is ascertained by including interaction in the regression (the last model in Table 5). None of the interactions are significant, i.e., regions are similar in the effects on market orientation.

Market orientation is consequential. Notably, market orientation is related to the income of the social entrepreneur, in that a strong market orientation is linked to high income.

\subsection{Reinvestment in social enterprises}

The first question about reinvestment, measured numerically as described earlier, is whether it differs between the two regions. Reinvestment averages 3.57 in Europe and 3.86 in MENA. This difference is significant $(p=0.002)$.

A further question is, how is reinvestment affected by characteristics of the social entrepreneurs and the enterprise? Effects are ascertained in a linear regression (Table 6, first model).

Reinvestment is affected by gender, in that reinvestment is less for female than for male social entrepreneurs.

Reinvestment is affected by neither age nor education.

Reinvestment is coupled with the values of the social enterprise. Reinvestment is high when value is attached to society and environment rather than to the economy of the enterprise. Reinvestment is especially high when value is granted the social rather than the environmental. 
Table 6 Reinvestment in social enterprises, affected by gender, age, education and region

\begin{tabular}{lcc}
\hline Region (Europe 0, MENA 1) & 0.125 & -0.459 \\
Gender (male 0, female 1) & $-0.210^{* *}$ & $-0.206^{* *}$ \\
Age & -0.002 & -0.001 \\
Education & -0.012 & -0.013 \\
Value for society and environment rather than economy & $0.219^{* * *}$ & $0.206^{* * *}$ \\
Value for social rather than environment & $0.121^{* * *}$ & $0.110^{* * *}$ \\
Region * value for society and environment rather than economy & & 0.135 \\
Region * value for social rather than environment & & 0.071 \\
Region * gender & & -0.082 \\
Region * age & & -0.010 \\
Region * education & & 0.012 \\
Intercept & $2.672^{* * *}$ & $2.735^{* * *}$ \\
N social entrepreneurs & 1,879 & 1,879 \\
\hline
\end{tabular}

Notes: Linear regression with metric coefficients. ${ }^{*} \mathrm{p}<0.05,{ }^{* *} \mathrm{p}<0.01$ and $* * * \mathrm{p}<0.001$.

A further question is whether such effects on reinvestment differ between the two regions. This is tested by the interactions in the last model in Table 6. None of the interactions are significant, so the effects are similar in Europe and MENA.

\subsection{Innovation in social enterprises}

The first question about innovation, measured numerically as described earlier, is whether it is similar or different in Europe and MENA. Innovation averages 2.70 in Europe and 3.45 in MENA. The difference is significant $(\mathrm{p}<0.001)$.

A next question is, how is innovation affected, not only by region, but also by background of the social entrepreneur and the enterprise. Effects are ascertained by linear regression (Table 7, first model).

Region affects innovation, also when controlling for characteristics of the entrepreneur and the enterprise, in that innovation is higher in MENA than in Europe. Innovation is not discernible affected by gender, and neither by education. Age affects innovation, in that elderly tend to be less innovative than younger social entrepreneurs. Entrepreneurial competence, measured as an index of self-efficacy, opportunity-alertness, risk-willingness and acquaintance with an entrepreneur, promotes innovation. Market orientation of the social enterprise also promotes innovation.

A further question is whether such effects on innovation differ between the regions. This is tested by the interactions in the last model in Table 7.

The regions are similar in the effects upon innovation from characteristics of the social entrepreneur.

Market orientation has different effects in Europe and in MENA, in that market orientation promotes innovation more in MENA than in Europe. 
Innovation has consequences for other outcomes of the social enterprise. Innovation expectedly promotes growth-expectation. This is seen by a positive correlation between innovation and growth-expectation. This positive effect of innovation is distinct from effects of region and characteristics of the social entrepreneur and the enterprise, as examined next.

Table 7 Innovation in social enterprises, affected by region, gender, age, education, competence and market orientation

\begin{tabular}{lcc}
\hline Region (Europe 0, MENA 1) & $0.687^{* * *}$ & $1.060^{*}$ \\
Gender (male 0, female 1) & -0.042 & -0.036 \\
Age & $-0.004^{*}$ & -0.003 \\
Education & -0.005 & 0.003 \\
Competence & $0.432^{* * *}$ & $0.435^{* * *}$ \\
Market orientation & $0.375^{* * *}$ & $0.356^{* * *}$ \\
Region * gender & & -0.040 \\
Region * age & & -0.009 \\
Region * education & & -0.033 \\
Region * competence & & -0.104 \\
Region * market orientation & $1.462^{* * *}$ & $0.146 * *$ \\
Intercept & 1,941 & $1.361 * * *$ \\
N social entrepreneurs & & 1,941 \\
\hline
\end{tabular}

Notes: Linear regression with metric coefficients. ${ }^{*} \mathrm{p}<0.05,{ }^{* *} \mathrm{p}<0.01$ and $* * * \mathrm{p}<0.001$.

\subsection{Expectation for growth of social enterprises}

A first question about expectations for growth, measured numerically as described earlier, is whether they differ between the two regions. Growth-expectations average 0.32 in Europe and 0.55 in MENA. The difference is significant $(p=0.01)$. Thus expectations for growth of social enterprises are higher in MENA than in Europe.

A further question is whether expectations are affected, not only by region, but also by innovation and other characteristics of the social entrepreneur and the enterprise. This is tested by linear regression (Table 8 , first model).

The effect of region vanishes when taking into account characteristics of the entrepreneur and the enterprise. Characteristics of the entrepreneur - gender, age and education - have no discernible effects on expectation for growth. But characteristics of the enterprise affect expectations. Using informal and formal sources of financing are coupled with high expectations. Also innovation raises expectations for growth.

A further question is whether effects on expectations differ between the two regions. Differential effects are ascertained by including interactions in the regression (Table 8 , last model). None of the interactions are significant, i.e., the characteristics of entrepreneurs and their enterprises have similar effects in Europe and in MENA. 
Table 8 Expectation for growth in social enterprises, affected by region, gender, age, education and innovation

\begin{tabular}{lcc}
\hline Region (Europe 0, MENA 1) & -0.142 & 0.251 \\
Gender (male 0, female 1) & 0.069 & 0.050 \\
Age & 0.001 & 0.003 \\
Education & 0.017 & 0.018 \\
Informal sources of financing & $0.356^{*}$ & $0.425^{*}$ \\
Formal sources of financing & $0.336^{*}$ & $0.401^{*}$ \\
Innovation & $0.074^{*}$ & $0.074 *$ \\
Reinvestment & 0.001 & -0.003 \\
Region * gender & & 0.301 \\
Region * age & & -0.008 \\
Region * education & & -0.026 \\
Region * informal sources of financing & & -0.618 \\
Region * formal sources of financing & & -0.666 \\
Region * innovation & & 0.056 \\
Region * reinvestment & & 0.079 \\
Intercept & -0.132 & -0.197 \\
N social entrepreneurs & 418 & 418 \\
\hline
\end{tabular}

Notes: Linear regression with metric coefficients. ${ }^{*} \mathrm{p}<0.05,{ }^{* *} \mathrm{p}<0.01$ and $* * * \mathrm{p}<0.001$.

\subsection{Social enterprises' assessment of their social and environmental impact}

The first question about assessments of impacts of social enterprises, measured numerically as described earlier, is whether assessments differ between Europe and MENA. The extent of conducting assessments average 3.67 in Europe and 3.78 in MENA. The small difference is not significant $(\mathrm{p}=0.22)$.

A next question is, how the conduct of assessments depends on characteristics of the social entrepreneur and the enterprise. This tested by linear regression (Table 9, first model).

Gender affects the conduct of assessment, in that assessments are conducted more for female-led enterprises than for male-led enterprises.

Age affect assessments, which are more extensive in enterprises led by elderly than in enterprises led by younger social entrepreneurs.

Education affects assessments, which are conducted more in enterprises led by educated entrepreneurs than in enterprises led by less educated entrepreneurs.

Market orientation promotes the conduct of assessments.

Assessments is also more extensive when society and the environment is valued rather than the economy of the enterprise. 
Table 9 Conduct of assessments of impact of social enterprises, affected by region, gender, age, education, market orientation, and values

\begin{tabular}{lcc}
\hline Region (Europe 0, MENA 1) & 0.074 & -0.535 \\
Gender (male 0, female 1) & $0.123^{*}$ & $0.129^{*}$ \\
Age & $0.004^{*}$ & $0.005^{*}$ \\
Education & $-0.026^{* *}$ & $-0.024^{*}$ \\
Market orientation & $0.320^{* * *}$ & $0.321^{* * *}$ \\
Value for society and environment rather than economy & $0.150^{* * *}$ & $0.144^{* * *}$ \\
Value for social rather than environment & 0.012 & -0.020 \\
Region * gender & & -0.118 \\
Region * age & & -0.010 \\
Region * education & & 0.004 \\
Region * market orientation & & -0.034 \\
Region * value for society and environment & & 0.012 \\
Region * value for social rather than environment & & $0.274^{* * *}$ \\
Intercept & $1.976^{* * *}$ & $2.049^{* * *}$ \\
N social entrepreneurs & 1,851 & 1,851 \\
\hline
\end{tabular}

Notes: Linear regression with metric coefficients. ${ }^{*} \mathrm{p}<0.05$, ${ }^{* *} \mathrm{p}<0.01$ and $* * * \mathrm{p}<0.001$.

A final question is whether effect on the conduct of assessments of impact differs between the regions. This is tested by including interactions in the regression (Table 9, last model). Assessment is especially extensive in MENA in enterprises that value social rather than environmental matters.

\section{Conclusions}

The research question has been, how is social entrepreneurship pursued in Europe and in the MENA? We here summarise our findings, admit limitations, and suggest further research.

\subsection{Summary of findings}

The typical studies of social entrepreneurship are conducted within a single country, thus limiting contextualisation and constraining the possibility of understanding embeddedness in economy and culture. Our study is thus a leap forward by systematic comparison across quite different economies and cultures.

Participation in social entrepreneurship is wider in Europe than in MENA. Education promotes participation in MENA and especially in Europe.

Value to society and the environment rather than to the economy of the social enterprise is prominent in social enterprising MENA more than in Europe. Social and environmental value is especially high for social entrepreneurs who are females, elderly and educated. 
Value to society rather than to the environment is emphasised in social enterprising in MENA more than in Europe, especially by female and educated social entrepreneurs.

Informal sources of financing for social enterprises are used more in MENA than in Europe, but, conversely, formal sources are used more in Europe than in MENA. In MENA young entrepreneurs have especially little access to formal sources.

Market orientation is enhanced in social enterprises that value the economy rather than society and the environment.

Reinvestment is more typical among male than female social entrepreneurs and is high when society and environment are valued rather than the economy of the enterprise, and is especially high where society is valued rather than the environment.

Innovation in social enterprises is higher in MENA than in Europe, is enhanced by entrepreneurial competence of the social entrepreneur and by market orientation, and is especially high in market oriented enterprises in MENA.

Growth-expectation is coupled with use of informal and formal sources of financing and is promoted by innovation.

Assessment of impact is more extensive for female-led enterprises and less extensive for educated social entrepreneurs. Assessment is promoted by market orientation, and in enterprises valuing society and environment, rather than economy. Assessment is especially extensive in enterprises in MENA which emphasise the social rather than the environmental.

\subsection{Limitations}

Although our comparison across economies and cultures is a leap forward, a major limitation is that we only compared across two regions.

\subsection{Further research}

The comparison between Europe and MENA has revealed several differences that may be caused by their differences in economy and culture. Knowledge about social entrepreneurship may be expanded by comparisons among several societies around the world and by explicitly modelling the impact of institutions. The analysis of impact of institutions was begun by Monge (2018) and is worthwhile continuing.

Turning from conditions to consequences, it is feasible to analyse, comparatively and globally, how social enterprising affect development of societies and their social life (Mair and Marti, 2006; Saebi et al., 2019).

\section{References}

Abdou, E. et al. (2010) Social Entrepreneurship in the Middle East [online] https://silatech.org/wpcontent/uploads/2018/12/social-entrepreneurship-in-the-middle-east-toward-sustainabledevelopment-for-the-next-generation.pdf (accessed 28 August 2020).

Austin, J., Stevenson, H. and Wei-Skillern, J. (2006) 'Social and commercial entrepreneurship: same, different, or both?', Entrepreneurship Theory and Practice, Vol. 30, No. 1, pp.1-22.

Bhattarai, C.R., Kwong, C.C.Y. and Tasavoria, M. (2019) 'Market orientation, market disruptiveness capability and social enterprise performance: an empirical study from the United Kingdom', Journal of Business Research, Vol. 96, pp.47-60, Elsevier Inc [online] https://doi.org/10.1016/j.jbusres.2018.10.042. 
Bornstein, D. (2004) Comment changer le monde: Les entrepreneurs sociaux et le pouvoir des idees nouvelles, La découverte.

Bosma, N., Schøtt, T., Terjesen, S. and Kew, P. (2016) Global Entrepreneurship Monitor 2015 to 2016: Special Report on Social Entrepreneurship [online] http://www.gemconsortium.org (accessed 1 September 2020).

Defourny, J. and Nyssens, M. (2010) 'Conceptions of social enterprise and social entrepreneurship in Europe and the United States: convergences and divergences', Journal of Social Entrepreneurship, Vol. 1, No. 1, pp.32-53.

Demirbag, M., McGuinnness, M., Wood, G. and Bayyurt, N. (2015) 'Context, law and reinvestment decisions: why the transitional periphery differs from other post-state socialist economies', International Business Review, Vol. 24, DOI: 10.1016/j.ibusrev.2015.03.003.

Global Entrepreneurship Research Association (2020) [online] http://www.gemconsortium.org (accessed 1 September 2020).

Hoogendoorn, B., Pennings, E. and Thurik, R. (2010) 'What do we know about social entrepreneurship? An analysis of empirical research', International Review of Entrepreneurship, Vol. 8, No. 2.

Jamali, D., Mohanna, N., Sherif, D.H. and El Sayeh, S. (2016) 'A comparative study of social enterprises: north vs. south perspectives', IntechOpen [online] https://pdfs.semanticscholar. org/6cc7/d721a60325a6e5f0d27ed77b1169890766ab.pdf?_ga=2.50199014.1976182025.1573 044254-1501829543.1555771862 (accessed 1 September 2020).

Kabbaj, M., El Ouazzani, K., El Amrani, J. and Lemtaoui, M. (2016) 'A study of the social entrepreneurship ecosystem: the case of Morocco', Journal of Developmental Entrepreneurship, Vol. 21, No. 4, DOI: 10.1142/S1084946716500217.

Ma, Y., Kim, M., Heo, J. and Jang, L. (2012) 'The effects entrepreneurship and market orientation on social performance of social enterprise', International Conference on Economics Marketing and Management, p.6.

Mair, J. and Marti, I. (2006) 'Social entrepreneurship research: a source of explanation, prediction and delight', Journal of World Business, Vol. 41, pp.36-44.

Monge, C.B. (2018) 'Identifying cross-country key drivers of social entrepreneurial activity', Journal of Social Entrepreneurship, Vol. 9, No. 3, pp.181-199.

Moroccan Press Agency and HuffPost Morocco (2019) The Parliamentary Opening: the Full Text of the Royal Speech, 11 October [online] https://www.huffpostmaghreb.com/entry/rentreeparlementaire-voici-le-texte-integral-du-discours-royal_mg_5da04680e4b02c9da048642c (accessed 6 November 2019).

Peredo, A. and McLean, M. (2006) 'Social entrepreneurship: a critical review of the concept', Journal of World Business, Vol. 41, No. 1, pp.56-65.

Perrini, F. and Vurro, C. (2006) 'Social entrepreneurship: innovation and social change across theory and practice', in Mair, J., Robinson, J. and Hockerts, K. (Eds.): Social Entrepreneurship, Palgrave Macmillan, New York.

Phillips, W., Lee, H., Ghobadian, A., O'Regan, N. and James, P. (2014) 'Social innovation and social entrepreneurship: a systematic review', Group \& Organization Management, Vol. 40, No. 3, pp.1-34.

Potocan, V., Nedelko, Z., Peleckienė, V. and Peleckis, K. (2019) 'Values, environmental concern and economic concern as predictors of enterprise environmental responsiveness', Journal of Business Economics and Management [online] https:/www.tandfonline.com/doi/abs/10.3846.

Saebi, T., Foss, N.J. and Linder, S. (2019) 'Social entrepreneurship research: past achievements and future promises', Journal of Management, Vol. 45, No. 1, pp.70-95.

Santos, F., Pache, A. and Birkholz, C. (2015) 'Making hybrids work: aligning business models and organizational design for social enterprises', California Management Review, Vol. 57, No. 3, pp.36-58 (accessed 28 August 2020). 
Schneider, L. et al. (2015) 'Assessing environmental and social impacts', Econsense, October [online] https://econsense.de/app/uploads/2018/06/econsense_Assessing-Environmental-andSocial-Impacts_2015.pdf (accessed 28 August 2020).

Stephan, U., Uhlaner, L.M. and Stride, C. (2014) 'Institutions and social entrepreneurship: the role of institutional voids, institutional support, and institutional configurations', Journal of International Business Studies, Vol. 46, No. 3, pp.308-331.

Sud, M., VanSandt, C.V. and Baugous, A.M. (2008) 'Social entrepreneurship: the role of institutions', Journal of Business Ethics, Vol. 85, No. S1, pp.201-216.

Wellalage, N.H. and Reddy, K. (2017) 'Determinants of profit reinvestment undertaken by SMEs in the small island countries', Global Finance Journal, DOI: 10.1016/j.gfj.2017.11.001. 